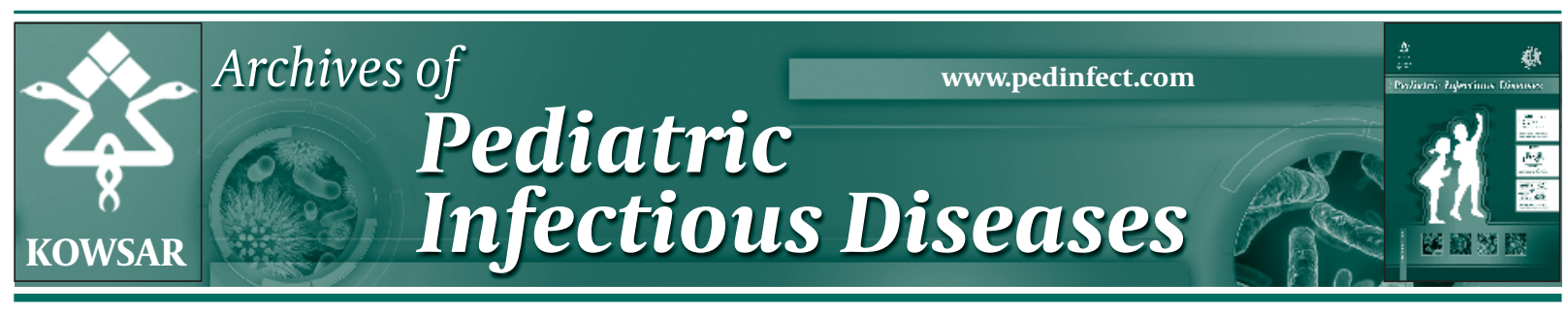

\title{
Should We Simply Rely on International Guidelines in Our Clinical Practice?
}

\author{
Mostafa Sharifian ${ }^{1,2, *}$ \\ ${ }^{1}$ Pediatric Infections Research Center, Shahid Beheshti University of Medical Sciences, Tehran, IR Iran \\ 2 Pediatric Nephrology Research Center, Shahid Beheshti University of Medical Sciences, Tehran, IR Iran \\ * Corresponding author: Mostafa Sharifian, 1) Pediatric Infections Research Center, 2) Pediatric Nephrology Research Center, Shahid Beheshti University of \\ Medical Sciences, Tehran, IR Iran.Tel.: +98-2122226941, Fax: +98-2122220254, E-mail: sharifian.dorche@gmail.com
}

Keywords: Guidelines as Topic; Physician's Practice Patterns

Pattern of health problems widely depends on age, gender, race, genetics, economic and health policy characteristics. In neonatal care unit, most of the times we face with conditions such as sepsis, respiratory distress syndrome (RDS), Icter and congenital anomalies. Infants are more prone to gastroenteritis, cold, other viral infections, meningitis, pneumonia, rickets and so on. Toddlers can now walk around and drink fascinating colored liquids such as antifreeze (Ethylene glycol), so they are more prone to foreign body aspirations and intoxications.

Because of going to kindergartens, Preschool aged children usually suffer from recurrent upper respiratory infections in winters or gastroenteritis in summer. In school ages, children are faced toinfection related complications such as rheumatic fever (RF) and post infectious glomerulonephritis. In industrial countries, acute rheumatic fever incidence rate has declined recently, due to better care and less incidence of infectious diseases like streptococcal pharyngitis (1-4).

Based on the progress in health care, control of infectious diseases and new data on the efficacy of prophylaxis, the American academy of pediatrics (AAP) presented their new guideline to manage urinary tract infection (UTI) in children aged 2-24 months. According to this practical guideline (5), if a child has first simple UTI, imaging studies even ultrasonography is not necessary. According to this guideline, we can ignore any harmful and unnecessary procedures and radiation exposure, voiding cysto-urethrography (VCUG) or dimercapto succinic acid (DMSA) isotope scan.

Two months ago, a 14 years old boy referred to our nephrology ward with a febrile seizure. His blood pressure was around 210/105 mmHg. His urine analysis and urine culture revealed a UTI. In the history, he and his family denied any previous attack of UTI and apparently this was the first infection.

Ultrasonography reported bilateral hydroureteronephrosis and VCUG showed bilateral grade 5 vesicoureteral reflux (VUR) with tortuous ureter. In addition, he had multiple bilateral renal scars in his DMSA scan with a glomerular filtration rate (GFR) of around $70 \mathrm{~mL} / \mathrm{min} / 1.73$ $\mathrm{m}^{2}$.

Obviously, it was not his first UTI since renal scar needs at least 6 months to develop. Due to the traditional cul-

-Article type: Editorial; Received:12 Dec 2012, Accepted: 30 Dec 2012; DOI:10.5812/pedinfect.10187

-Implication for health policy/practice/research/medical education:

This article is useful for health providers.

P Please cite this paper as:

Sharifian M. Should We Simply Rely on International Guidelines in Our Clinical Practice? Arch Pediatr Infect Dis.2013;1(2): 41-43. DOI: 10.5812/pedinfect.10187

Copyright (C) 2013, Pediatric Infections Research Center

This is an Open Access article distributed under the terms of the Creative Commons Attribution License (http://creativecommons.org/licenses/by/3.0), which permits unrestricted use, distribution, and reproduction in any medium, provided the original work is properly cited. 
ture of the family they wrongly attributed his first infancy febrile attack (fever without localizing sign) to a dental eruption and the second time they considered it as a kind of gastroenteritis so several UTI episodes have been missed and left untreated.

In the second history, a simple common disease was missed by health personnel. The patient M.A is a teen age boy from a city in east central part of the country. He presented and admitted with arthralgia in lower limb, generalized edema, ascitis, melena, petechia and hematuria; in local hospital, diagnosis of Henoch Schoenlein Purpura (HSP) with renal complications was made and treatments with Prednisolone were started. About 4 days later edema, ascitis and petechia were better but renal function deteriorated and BUN and $\mathrm{Cr}$ had rising trend; for this reason, he was referred to our hospital. At presentation, he had periorbital edema, low grade fever, pan systolic murmur in the heart and splinter hemorrhage in subungual area. Bacterial endocarditis was considered and echocardiography revealed medium size $(7 \mathrm{~mm})$ vegetation on atrial surface of anterior Mitral valve (MV) leaflet, moderate aortic insufficiency (AI) and moderate Mitral regurgitation (MR). Treatment of endocarditis was prescribed and peritoneal dialysis (PD) started as his blood urea nitrogen (BUN) was around 180 and creatinine around 5-6 mg/dL. At routine follow-up renal function remained stable but proteinuria remained in the nephrotic range, renal biopsy was performed. The results findings were compatible with Membrano proliferative glomerulonephritis (MPGN). Based on renal biopsy result; high dose methyl Prednisolone pulses was initially prescribed in 3 days and continued with high dose oral Prednisolone. Lastly, he is receiving Prednisolone $50 \mathrm{mg}$ alternate day and Mycophenolate Mofetil 500 mg twice daily. This resulted in a dramatic decrease in proteinuria from nephritic range to trace in urinalysis and around $300 \mathrm{mg}$ in 24 hours collection.

In this situation; detailed history was taken and revealed that:

At the age of 6 years, he has had sore throat and high fever (symptoms and signs of pharyngitis); it was treated only with Acetaminophen as having a cold, two weeks later when he presented with migrating arthritis the pain was referred as weakness and growing pain and rheumatic fever (RF) was missed and left untreated. Several months later when he was unwell and had fatigue and exercise intolerance again, it ascribed as hypovitaminosis and multivitamins was prescribed. Retrospectively looking, at this stage he probably has had a rheumatic carditis which was missed. Again, it was left untreated, the low grade fever and fatigue continued and he got Sub acute bacterial endocarditis (SBE) with one of its complications which were severe glomerulonephritis of chronic infection leading to renal failure (RF) requiring dialysis.

This case is an extreme example of missing a simple dis- ease, which progressed to a dramatic and life threatening process ie: RF, bacterial endocarditis and MPGN. This patient did not have GN days or weeks after throat infection as is in his history and is usual for PSGN (6-10); but his GN is the endpoint after bacterial endocarditis.

The life threatening process of an easily treatable pharyngitis which ended to a challenging and difficult disease in terms of treatment (11), is the result of lack of a routine physical examination of patient when comes with fever in clinic which has happened in this patient for several times.

In a study on Microbial sensitivity pattern in urinary tract infections in children (12) we found that in our center the microorganisms causing UTI are more than 70\% resistant to Ampicillin, Amoxicillin, and Cotrimoxazole and pseudomonas are $100 \%$ resistant to these antibiotics still; these antibiotics are among the first choices for treatment of UTIs in most textbooks and references. The high incidence of resistant antibiotics is the result of unsuitable usage of antibiotics in our environment.

In conclusion, these evidences suggest that the economic and cultural issues can alter the pattern of presentation of patients and have profound influence on our treatment success. International guidelines although very helpful and valuable in managing common and important diseases reducing the cost and drawback of delaying diagnosis and treatment especially for junior staff; should be modified based on local studies and experiences. We reemphasize the value of physical examination before any lab test and imaging study and before any prescription.

\section{Authors' Contribution}

None declared.

\section{Financial Disclosure}

None declared.

\section{References}

1. Bonita F, Kliegman RM, Stanton BF, Schor NF, St. Geme III JW, Behrman RE. Nelson Textbook of Pediatrics. 19th. Philadelphia: WB Saunders Elsevier; 2011; p. 1-17

2. Kliegman RM, Stanton BF, Schor NF, St. Geme III JW, Behrman RE, Pan CG, Avner EO. Nelson Textbook of Pediatrics. 19th. Philadelphia: WB Saunders Elsevier; 2011. p. 1783-7.

3. Avner ED, Harmon WE, Niaudet P, Yoshikawa N, Rodrı'guezIturbe B, Mezzano S. Pediatric Nephrology. Verlag Berlin Heidelberg: Springer; 2009. p. 743-55.

4. Marcdante KJ, Kliegman RM, Jenson HB, Behrman RE, Mahan JD. Nelson Essential of Pediatrics. 2011; p. 607-23

5. Roberts KB. Urinary tract infection: clinical practice guideline for the diagnosis and management of the initial UTI in febrile in fants and children 2 to 24 months. Pediatrics. 2011;128(3):595-610.

6. Oparil S, Weber MA. Hypertension: a companion to Brenner and Rector's the kidney. Elsevier Mosby; 2005.

7. Lunn A, Forbes TA. Haematuria and proteinuria in childhood. Paediatr Child Health. 2012;22(8):315-21.

8. Sethi S, Fervenza FC. Membranoproliferative glomerulonephritis-a new look at an old entity. N Engl J Med. 2012;366(12):1119-31.

9. Sethi S, Sukov WR, Zhang Y, Fervenza FC, Lager DJ, Miller DV, et al. 
Dense deposit disease associated with monoclonal gammopathy of undetermined significance. Am J Kidney Dis. 2010;56(5):977-82.

10. Lorcy N, Rioux-Leclercq N, Lombard ML, Le Pogamp P, Vigneau C. Three kidneys, two diseases, one antibody? Nephrol Dial Transplant. 2011;26(11):3811-3.

11. Hamano Y, Yoshizawa H, Sugase T, Miki T, Ohtani N, Hanawa $S$, et al. Rituximab Treatment for PR3-ANCA-Positive Mem- branoproliferative Glomerulonephritis Associated with Adult-Onset Periodic Fever Syndrome. Case Rep Nephrol Urol. 2012;2(2):92-101.

12. Sharifian M, Karimi A, Tabatabaei SR, Anvaripour N. Microbial sensitivity pattern in urinary tract infections in children: a single center experience of 1,177 urine cultures. Jpn J Infect Dis. 2006;59(6):380-2. 